\title{
Problems Existing in Measurement of Liquid Flash Point and Upswing Measures of Experiment Process

\author{
QI Li-ming ${ }^{1, a}$, ZHAO Rong ${ }^{2, b}$, GE Xu-bin ${ }^{3, c}$
}

${ }^{1}$ School of Safety Engineering, North China Institute of Science \& Technology, Beijing 101601, China

${ }^{2}$ Graduate School, North China Institute of Science \& Technology, Beijing 101601, China

${ }^{3}$ Graduate School, North China Institute of Science \& Technology, Beijing 101601, China

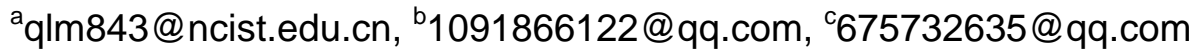

Keywords: Flash point; Experiment teaching; Safety; Precise

\begin{abstract}
Measurement of liquid flash point is one of important experiments to safety engineering specialty. Its importance was analyzed by author and its available measurement methods were introduced. Then problems in teaching process of liquid flash point measurement were analyzed. Finally, some measures were brought forward to improve experiment conditions in existence.
\end{abstract}

\section{Introduction}

Statistics show that there have been 86 colleges setting undergraduate professional of safety engineering in China [1]. Its target is to cultivate advanced persons who will be engaged in evaluation, design, construction, management, supervision and labor protection in the field of safety engineering [2]. Therefore, some courses involved fire have been set among course system of safety engineering specialty, including experiment course to measure liquid flash point [3-7].

Flash point is the lowest temperature that flash can take place at the surface of liquid under the specified experiment conditions [8]. It is an index that is used to judge fire risk of flammable liquid, also is a basis to classify the first, second and third hazardous liquid. The fire resistance level, fire prevention distances and explosion prevention facilities of plants and storehouses that produce or save flammable liquid are determined by flash point. Flash point is one of bases to determine fire extinguishing agent's furnishing quantity too $[9,10]$.

Flash point experiment dates back to 19th century, and it was used to measure quality of fuel and lube at that time. Closed-cup flash point experiment was invented by Berthold Pensky who is Germany. Furthermore, Berthold Pensky, coupled with Kaiser Wilhelm Institute, drafted recognized Pensky-Martens method. GB/T261and SH/T0733 are primary closed-cup methods to measure flash point in China [11].

Based on closed-cup flash point measurement and its steps, problems of available method and corresponding improved measures were discussed.

\section{Importance to measure liquid flash}

Flammable liquid's boiling point is lower than its ignition point. And its combustion process is that fuels evaporate into steam firstly, and then it will be mixed with air for burning, which indicates that it is different from flammable gas's combustion process. The combustion process is shown as Fig.1. 


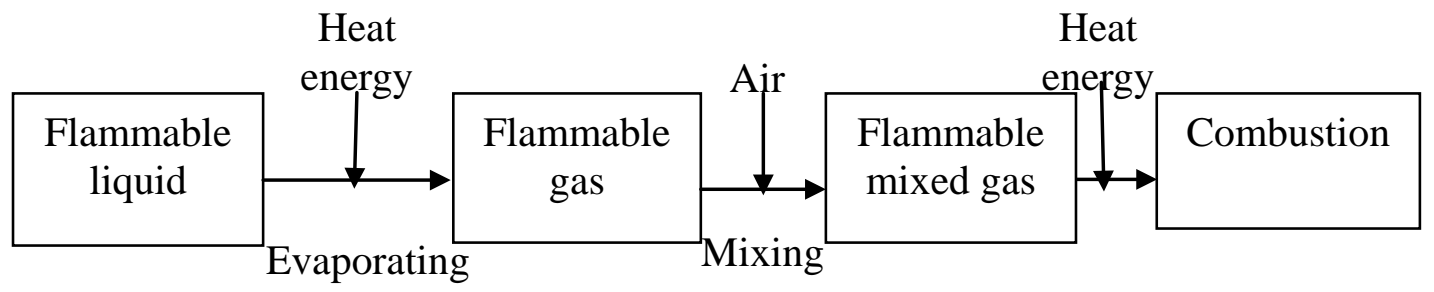

Fig.1 Combustion process of flammable liquid

According to vapor pressure theory, there is a one-to-one relationship between its temperature and vapor pressure or vapor concentration for given flammable liquid. When vapor concentration reaches upper limit or lower limit of explosion, corresponding temperatures are upper limit or lower limit of explosion temperature respectively that are expressed by $t_{u}$ and $t_{1}$. Besides, lower limit of explosion temperature is actually flash point. It is shown as Fig.2.

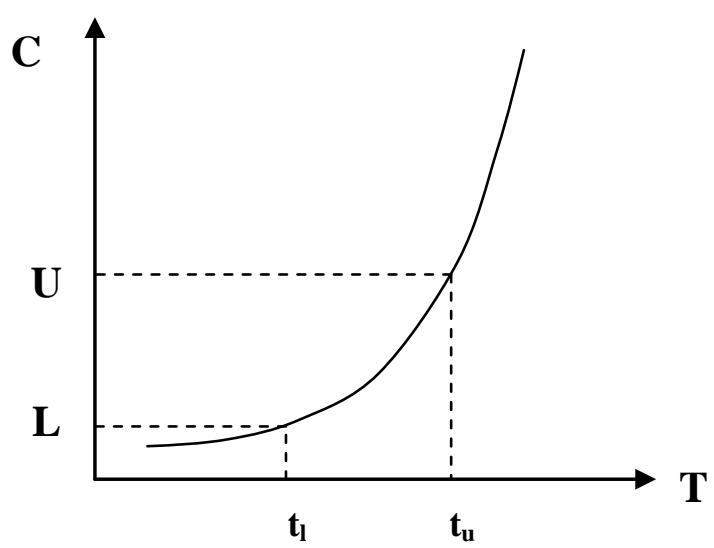

Fig.2 Corresponding relation of liquid temperature and vapor concentration

In Fig.2, $\mathrm{T}$ represents flammable liquid's temperature, $\mathrm{C}$ represents its vapor concentration, $\mathrm{L}$ is lower limit of vapor explosion concentration, and $U$ is upper limit of vapor explosion concentration. If ambient temperature is higher than flash point, its saturation vapor concentration or unsaturated vapor concentration will be in the scope of vapor explosion concentration. Once meeting fire, explosion or combustion will take place. Therefore, flash point is an important basis to evaluate fire risk of flammable liquid.

For flammable liquid, it is necessary to measure its flash point accurately in order to prevent explosion and combustion effectively and carry out corresponding safety measures. Therefore, measuring flash point is reviewed as an important experiment in the teaching scheme of safety engineering specialty.

\section{Brief introduction of measuring flash point}

Its measuring equipment is shown in Fig.3.

\section{Experiment principle}

With liquid's temperature increasing, vapor concentration above liquid will also increase gradually. If it increases to lower limit of explosion and meets fire, flash will take place. And corresponding temperature is flash point of this liquid.

\section{Experiment steps}

Now, taking diesel oil as an example, introduce the measurement of flash point steps.

1) Inject oil into cup until liquid surface reaches orbicular sign marked on cup;

2) Cover oil cup, connect mixing flexible axle, plug into a thermometer, open electrical source, adjust voltage (about 40 50 V), and open mixing switch;

3) Drop voltage to $10 \sim 20 \mathrm{~V}$ when temperature reaches $40^{\circ} \mathrm{C}$ for slowing down calefaction 
velocity;

4) Open switch of liquefied gas container, and then open pressure reducing valve, ignite the ignition at the same time;

5) Adjust adjustment screw of ignition to make flame to be a sphere whose diameter is about 3 4mm;

6) Close mixing switch when temperature reaches $55^{\circ} \mathrm{C}$, and then revolve ignition knob to start ignition experiment;

7) Record thermometer's reading $t_{1}$ and atmospheric pressure $P_{1}$ if blue flame appears, and then close switch of liquefied gas container, pressure reducing valve and electrical source. Finally, open oil cup to take it out for cooling. Heat it again to measure the second group data;

8) But if blue flame does not appear, continue to heat. It requires to revolve ignition knob when temperature increases by $1 \sim 2^{\circ} \mathrm{C}$ once to carry out ignition experiment. It won't be stopped until blue flame appears.

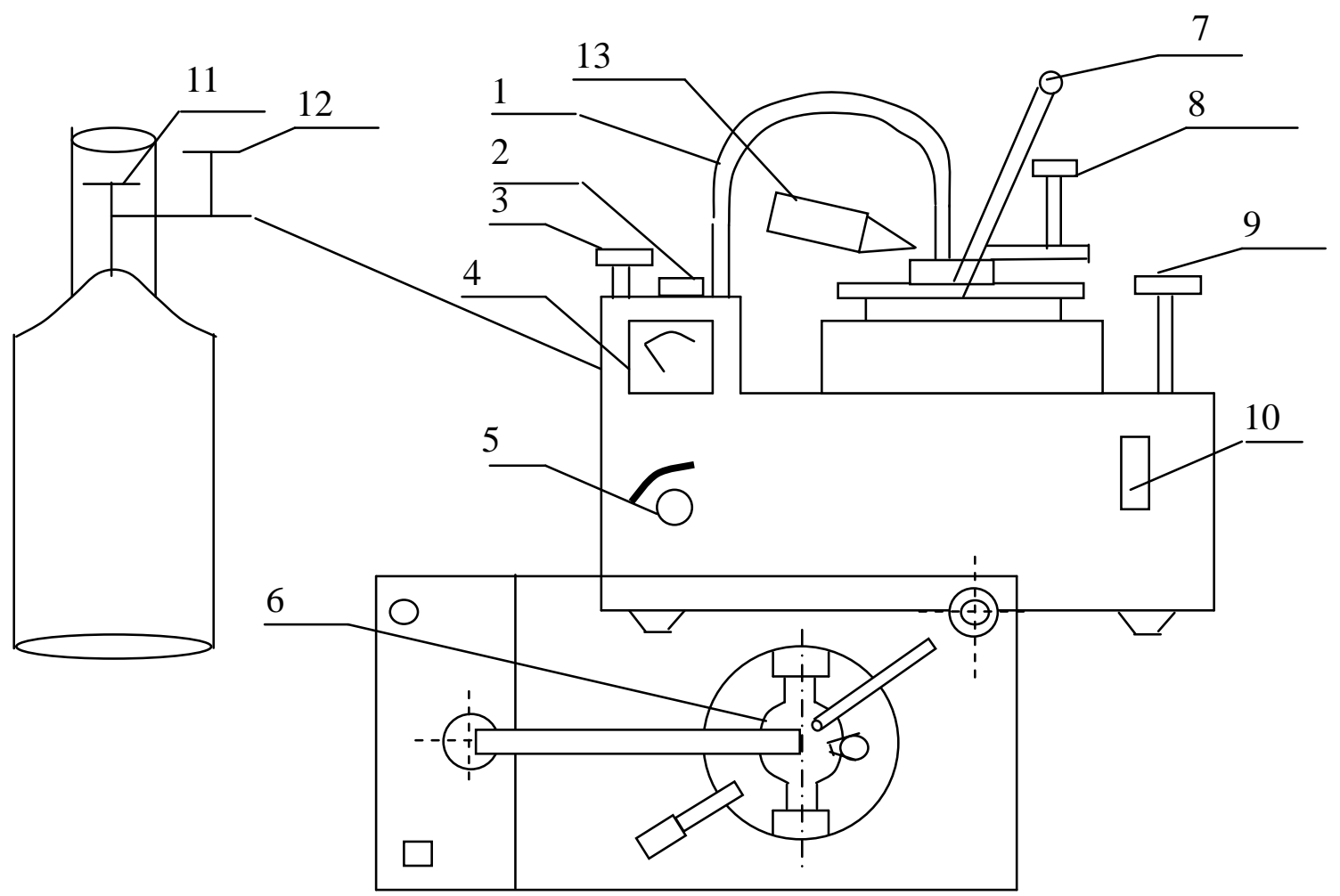

Fig.3 Experiment equipment of liquid flash point measurement

1 - mixing flexible axle; 2 - mixing switch; 3 - gas adjustment valve; 4 - voltmeter; 5 - voltage adjustment knob; 6 - oil cup; 7 - thermometer; 8 - ignition knob; 9 - oil cup stand; 10 - electrical source switch; 11- switch of liquefied gas container; 12 - pressure reducing valve; 13 - adjustment screw of ignition.

\section{Problems existing in the measurement of liquid flash point}

Following problems were found in the measurement of flash point after many times of instructing students to carry out experiment.

1) Liquefied gas container is used to ignite the fire, which increases the unsafe factor. Meanwhile, liquefied gas container is pushed over easily because of limited conditions and the great number of students.

2) Rotation direction of pressure reducing valve is reverse to others, leading easily students to operating it wrongly. As a result, velocity of gas flowing from liquefied gas container is very high. Once ignition kindled, a long flame will be formed that is easy to burn students.

3) Due to sealing requirement of closed-cup flash point experiment, certain physical strength is needed to open ignition knob. So it is difficult to conduct this step to students who are strength less 
or timid, especially to girls.

4) When observing flash phenomenon, part students maybe make a mistake that ignition's flame is flame produced by flash.

5) Flame is instable sometimes, so it is necessary to adjust it by adjustment screw. But its temperature is higher, which is likely to scald hand.

\section{Improvement measures of flash point measurement}

According to problems mentioned above, it is necessary to improve experiment conditions to ensure safety of experiment teaching and accuracy of results.

1) Increase the number of instruments; control the number of students guided by teacher, then divide them into groups to ensure experiment in good order.

2) Explain and emphasize the operational principle about pressure reducing valve repeatedly; mark switch's rotation direction observably.

3) Set the railings right in front of the air current outlet in case students stray into this field.

4) Add certain devices that can utilize lever principle in order to turn on ignition knob with less physical strength.

5) Add to several reflectors at experiment table, by which the interior of oil bottle can be observe to avoid the observation err with the help of teacher and other student.

6) Add a layer of higher heat capacity materials to adjusting screw in case of scald.

\section{Conclusions}

1) Flash point is an important index to evaluate fire risk of flammable liquid. Therefore, it is necessary to master measurement method of flash point and determine it accurately for students who major in safety engineering.

2) There have been five problems in measurement experiment of flash point at present, including two aspects: safety of person and accuracy of experiment results.

3) Six improvement measures were brought forward based on problems existing in measurement of flash point.

\section{Acknowledgements}

The research work was supported by National Natural Science Foundation of China (No.51204070), National Natural Science Foundation of Hebei Province (No.E2015508053), Fundamental Research Funds for the Central Universities (No. 2012E1202 and No.2011SYSJJ01) and Program for New Century Excellent Talents in University (No. NCET-11-0837).

\section{References}

[1] NIE Bai-sheng, ZHANG Jin-feng, HU Tie-zhu, etc, Setting undergraduate experimental courses of safety engineering discipline, J. Journal of Safety and Environment. 6 (2006) 14 16.

[2] LIU Rong, Building of safety engineering laboratory, J. Science and Technology of Safety. 1 (2003) 14 16.

[3] Qu Fang, Yuan Changming, Zheng Yingjun, Discussion on Education Model and Curriculum System of Safety Engineering Specialty, J. Industrial Safety and Environmental Protection. 30 (2004) 41 43.

[4] SA Zhan-you, WANG Yu-hua, ZHANG Yong-liang, etc, Courses system setting model of safety engineering specialty in Qingdao Technological University, J. Journal of Safety and Environment. 6 (2006) 42 44.

[5] TIAN Yun-li, LIAO Ke-bing, YI Can-nan, Probe in Innovational Education in Safety Engineering Disciplinary Experimental Course Teaching of and Its Practice, J. China Safety Science 
Journal. 16 (2006) 56 60.

[6] WANG Yu-hua, SA Zhan-you, ZHANG Yong-liang, etc, Discussion on building of safety engineering laboratory in Qingdao Technological University, J. Journal of Safety and Environment. 6 (2006) 40 41.

[7] ZHANG Ren-wei, JIANG Shu-guang, Discussion on Curriculum System of Safety Engineering Specialty in 21st century, J. Meitan Higher Education. 4 (2002) 61 62.

[8] LI Zeng-hua, Combustion, The Press of China University of Mining and Technology, Xuzhou 2003.

[9] LI Xi-zhe, Flash Point of Flammable Liquid, J. Health, Safety and Environment, 6 (2006) 51.

[10] LOU Jian-ming, FU Yue-qian, An implementation of least square method in oil flash-point measurement, J. Journal of Zhejiang Normal University. 26 (2003) 243 247.

[11] YUAN Han-ping, WANG Rui-rong, The Discussion on the Standard Test Methods for Determination of Petroleum Products Flashing Ppoint, J. Lubricating Oil. 20 (2005) 59 61. 